\title{
Numerical simulation of UCG process with the aim of increasing calorific value of syngas
}

\author{
Amin Jowkar ${ }^{1} \cdot$ Farhang Sereshki $^{1} \cdot$ Mehdi Najafi $^{2}$
}

Received: 2 June 2019/Revised: 24 September 2019/Accepted: 8 December 2019/Published online: 19 December 2019

(C) The Author(s) 2019

\begin{abstract}
The determination of operational parameters in the underground coal gasification (UCG) process should be considered in two aspects: first, the total coal in each UCG panel must be gasified and second, the calorific value of the produced gas should be acceptable. The main aim of this study is to present a model that meets these aspects and increasing the calorific value of syngas during this process. In order to achieve those aims, eight different increasing scenarios were devised for total gasification of coal per panel. These scenarios included: increasing oxygen injection rate (scenario 1), the amount of steam injection (scenario 2), operation time (scenario 3), cavity pressure (scenario 4), increase operation time and cavity pressure simultaneously (scenario 5), increase steam injection speed and oxygen injection rate simultaneously (scenario 6), increase in cavity pressure, operating time, steam injection rate and oxygen injection rate simultaneously (scenario 7) and also simultaneous increase in the operating time and steam injection rate (scenario 8). The results showed that for producing syngas with a higher calorific value, the following parameters had the most positive effects respectively: operation time, cavity pressure, steam injection rate and oxygen injection rate. Finally, the model validation was performed for the Centralia LBK-1 UCG pilot and the results showed that this model is very close to reality.
\end{abstract}

Keywords Underground coal gasification (UCG) · CFD simulation · Operational parameters · Calorific value of syngas

\section{Introduction}

Scientists are looking for different sources of energy because of limited oil and natural gas resources in the near future. Due to the specific chemical composition of coal, it has the potential to convert into oil and gas. Therefore, it is

Amin Jowkar

amin_jowkar@yahoo.com

Farhang Sereshki

fsereshki@shahroodut.ac.ir

Mehdi Najafi

mehdinajafi@yazd.ac.ir

1 Department of Mining Engineering, Petroleum and Geophysics, Shahrood University of Technology, Shahrood, Iran

2 Department of Mining and Metallurgical Engineering, Yazd University, Yazd, Iran one of the most important energy sources in the world (Smit and Werner 1976). On the other hand, conventional methods of extracting coal from underground sources are limited in high depth and variable thickness coal seams, so that only $5 \%$ of these resources can be exploited by conventional underground mining methods. According to literature view, if all reserves of the world's oil, gas and coal resources are considered $100 \%$, then $95.5 \%$ of those is coal (Couch 2009). This shows that investing and implementing long-term plans for coal exploitation in the future is crucial. Nowadays, one of the most popular methods of extracting coal seams is underground coal gasification (UCG). Over the past few decades, gas markets have been expanding more rapidly than other fossil fuels (Kasani and Chalaturnyk 2017).

In UCG process, in situ coal seams are converted into syngas by using an advanced thermochemical process (Robert and Joseph 1996). The most important gases produced in the UCG process are $\mathrm{CO}, \mathrm{CO}_{2}, \mathrm{H}_{2}$, and $\mathrm{CH}_{4}$, 
where the combination of them is called "syngas". In the UCG process, the goal can be to produce any gas (e.g. hydrogen) according to the type of gas required by the industry or to produce syngas. The gas generated by the UCG process can be used for electricity generation, municipal gas production and it also can be used in chemical industries such as methanol production, coal-toliquid process and natural hydrogen production (www.lin cenergy.com 2017).

To start operations on the project, a series of plans is needed to control the operation. In large projects, inaccurate design and planning can cause huge costs and damage. Therefore, more careful design and planning and testing prior to UCG operation will increase the likelihood of success in higher operation and efficiency. In the UCG method, this is particularly important because of the inability to direct personnel access to the basement as well as chemical interactions, geo-mechanical properties, groundwater and cogeneration heat inside the cavity. Therefore, without a proper model for degassing, it is dangerous to start this process. Many parameters affect the successful execution of UCG operations. These parameters can be classified into two categories: controllable and uncontrollable. Parameters such as oxidant injection rate, gas pressure inside the cavity, temperature and design parameters are controllable parameters. On the other hand, parameters such as the characteristics of the coal and surrounding rocks, the flow field of reactive gases inside the cavity, and the influx of water flow are uncontrollable parameters (Perkins 2005; Nourozieh et al. 2010; Sarraf Shirazi 2012; Daggupati et al. 2010).

Many studies has been done on the effect of operating parameters on the composition and calorific value of produced gas in the UCG process, and the most important are as follows. Perkins and Sahajwalla (2008) developed a Computational Fluid Dynamics (CFD) model to predict the composition and calorific value of the produced gas. Their results indicated that the calorific value of the produced gas is very sensitive to the coal reactivity and the exposed reactive surface area per unit volume in the channel. Daggupati et al. (2011) investigated cavity growth and the effect of operating parameters (such as the operation time and the composition of injected gas) on the calorific value of the produced gas. Andrianopoulos et al. (2015) simulated the chemical reactions in the UCG process using the Aspen Plus software, and finally examined the quality of the produced gas under different conditions. Zogala and Janoszek (2015) developed a CFD simulation using ANSYS Fluent software to examine the effect of steam as a gaseous agent on the composition and calorific value of the produced gas. The results of their studies showed that increasing the amount of steam leads to heightened calorific value of the produced gas to a certain point, after which the chemical reactions are affected due to decrease in temperature, and so the calorific value of the produced gas will decline. Laciak et al. (2016) simulated coal gasification process experimentally and explored the amount and composition of the produced gas under different compressive conditions. Wiatowski et al. (2016) investigated the composition and calorific value of the produced gas at different gasification times by simulating the UCG process in the laboratory under the maximum pressure of $5 \mathrm{MPa}$ and the maximum temperature of $1600{ }^{\circ} \mathrm{C}$. Kasani and Chalaturnyk (2017), simulated a UCG process for deep coal seams, this study aimed at conducting a sequentially coupled coal gasification and geomechanical simulation to study effects of the Alberta UCG on the coal seam and bounding seal system. Syngas compositions from this study have a good agreement with the field measurements. Perkins and Vairakannu (2017) in a study provided guidelines for the selection of the oxidant and gasifying medium through a combination of qualitative assessment and the use of a simplified cost model. Jiang et al. (2018) developed an environmental study of UCG process. It was found that cleats favour UCG production, and the prime operational parameter plays a dominant role in governing vertical mass transport in UCG. Iwaszenko et al. (2019) presented a new alternative way of the determination of kinetics of coal gasification by the random pore model application is proposed. The procedure for determination of model parameters is presented. Kumari and Vairakannu (2018) Presented a study that investigated the viability of utilizing the $\mathrm{CO}_{2}$-air as a gasifying medium for high ash Indian coals using a laboratory scale borehole gasification set-up in a two-stage gasification mode of operation. Su et al. (2018) constructed an artificial coal seam to use as a simulated underground gasifier, which comprised coal blocks excavated from the coal seam. The results showed that AE activities monitored during UCG process were significantly affected by operational variables such as feed gas rate, feed gas content, and linking-hole types.

It is clear that in most previous studies only the influence of one or more operating parameters on the composition and calorific value of the produced gas has been studied. None of these studies showed a model with changes in operating parameters to increase the calorific value of syngas and simultaneously the entire coal inside the cavity (one panel). Therefore, in this study a numerical model was developed by COMSOL software. In the presented model, the effect of operating parameters on the composition and calorific value of the produced gas can be predicted before implementing UCG process on a commercial scale. Further, the most suitable design can be selected for producing syngas with the highest calorific value. 


\section{Model development}

One of the major issues in the UCG method is to investigate the growth rate of the cavity volume. The cavity growth rate directly affects the amount of coal resource recovery and energy efficiency. As a result, it also affects the economic feasibility of the UCG process. The growth rate has also a direct influence on the shape of cavity in different directions. Studying the rate of cavity growth needs to examine its time-dependent behavior. In general, the mechanism of cavity growth rate can be investigated from chemical, mechanical, and thermal aspects simultaneously. The purpose of this study is to investigate the effects of operating parameters on chemical reactions and eventually to predict the calorific value of the produced gas. Accordingly, the cavity growth rate and the shape of the cavity were not investigated and a constant value was assumed for the volume. In this model, the total volume of the cavity (volume of panels) was constant. However, after the degassing operation, the volume of the cavity gradually increased to reach the total constant volume. Initial assumptions, coal properties, and chemical reactions, which are the main elements of the model, were then discussed separately in several stages. Finally, this simulation was investigated in COMSOL software.

\subsection{Dimensions of extraction cavities (panels)}

In this study, the parallel Controlled Retraction Injection Point (CRIP) method was selected to gasify a coal seam. Considering the thickness of coal seam as $3 \mathrm{~m}$, the transverse and longitudinal extension of coal seam, geological analysis, and past experiences, the distance between the injection and production wells was considered as $10 \mathrm{~m}$, and the distance between the injection and ignition wells was considered as $200 \mathrm{~m}$. Figure 1 demonstrates the dimensions of the considered panels.

The first step in this model is to determine the extraction cavity volume (panel) with respect to the coal seam thickness, extraction cavity size, and past experience. It should be noted that behind the injection wells there are some return gases, so the cavity volume is usually larger than the volume seen in Fig. 1. In this paper, the cavity

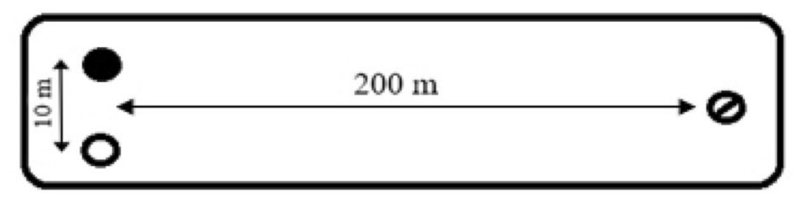

Injection well $\bigcirc$ Production well $\bigcirc$ Ignition well $\oslash$

Fig. 1 Panels' dimensions in the parallel CRIP method (top view volume was estimated according to the method explained by Jowkar et al. (2018). Therefore, according to Fig. 1 and considering the amount of backwardness, it is assumed that the total volume of the cavity is $7942 \mathrm{~m}^{3}$.

\subsection{Coal characteristics}

According to the cavity volume and the coal seam properties, the value of components in the cavity was calculated separately. The coal characteristics and its volatile substances can be provided as in Tables 1 and 2. Also coal density was assumed to be constant amount of $1.4 \mathrm{ton} / \mathrm{m}^{3}$.

Based on the data presented in Tables 1 and 2, using the molecular weights of each component in the cavity as well as the stoichiometric relationships, the amount of moles in the cavity is obtained in accordance with Table 3. For example, the amount of carbon in the cavity is calculated as follows: $\rho=m / v \rightarrow m=\rho v=1.4 \times 7942.138=$ 11118.993 ton $_{\text {coal }}$

$$
\begin{aligned}
C_{\text {fix }}= & 11118.993 \times 0.383=4258.574 \text { ton }_{\mathrm{c}} \\
\operatorname{mol}_{\mathrm{c}}= & 4258.574 \operatorname{ton}_{\mathrm{c}} \times 10^{6} \mathrm{~g}_{\mathrm{c}} / 1 \mathrm{ton}_{\mathrm{c}} \\
& \times 1 \mathrm{~mol}_{\mathrm{c}} / 12.011 \mathrm{~g}_{\mathrm{c}} \\
= & 354.556 \times 10^{6} \mathrm{~mol}_{\mathrm{c}}
\end{aligned}
$$

where $\rho, m, v$ and $C_{\text {fix }}$ are density, mass, volume and fixed carbon, respectively. Other components of volatile substances are negligible and have no effect on the nine main reactions occurring in the cavity.

\subsection{Investigating chemical reactions}

Chemical reactions that occur during the gasification process were carried out in homogeneous and heterogeneous phases (Perkins and Sahajwalla 2008). Further, the reactions in each of the two phases were investigated separately. The reactions occurred in the homogeneous phase are as follows: (Perkins and Sahajwalla 2008)

$$
\begin{aligned}
& \mathrm{H}_{2}+1 / 2 \mathrm{O}_{2} \rightarrow \mathrm{H}_{2} \mathrm{O} \\
& \mathrm{CO}+1 / 2 \mathrm{O}_{2} \rightarrow \mathrm{CO}_{2} \\
& \mathrm{CH}_{4}+2 \mathrm{O}_{2} \rightarrow \mathrm{CO}_{2}+2 \mathrm{H}_{2} \mathrm{O} \\
& \mathrm{CO}+\mathrm{H}_{2} \mathrm{O} \rightarrow \mathrm{CO}_{2}+\mathrm{H}_{2} \\
& \mathrm{CH}_{4}+\mathrm{H}_{2} \mathrm{O} \rightarrow \mathrm{CO}+3 \mathrm{H}_{2}
\end{aligned}
$$

Table 1 Hypothetical coal characteristics

\begin{tabular}{llll}
\hline $\begin{array}{l}\text { Moisture } \\
(\% \mathrm{w})\end{array}$ & $\begin{array}{l}\text { Ash yield } \\
(\% \mathrm{w})\end{array}$ & $\begin{array}{l}\text { Volatile matter } \\
(\% \mathrm{w})\end{array}$ & $\begin{array}{l}\text { Fixed carbon } \\
(\% \mathrm{w})\end{array}$ \\
\hline 7 & 24.3 & 30.4 & 38.3 \\
\hline
\end{tabular}


Table 2 Hypothetical characteristics for volatile matter

\begin{tabular}{llll}
\hline $\begin{array}{l}\mathrm{CH}_{4} \\
(\% \mathrm{w})\end{array}$ & $\begin{array}{l}\mathrm{CO}_{2} \\
(\% \mathrm{w})\end{array}$ & $\begin{array}{l}\mathrm{CO} \\
(\% \mathrm{w})\end{array}$ & $\begin{array}{l}\mathrm{NH}_{3}, \mathrm{CL}, \mathrm{N}_{2} \mathrm{O}, \mathrm{SO}_{2} \text { and other } \\
(\% \mathrm{w})\end{array}$ \\
\hline 10 & 8.4 & 7 & 5 \\
\hline
\end{tabular}

Table 3 The components and their value in the cavity

\begin{tabular}{lc}
\hline The components & Value $(\mathrm{Mmol})$ \\
\hline $\mathrm{C}$ & 354.556 \\
$\mathrm{H}_{2} \mathrm{O}$ & 43.204 \\
$\mathrm{CH}_{4}$ & 69.307 \\
$\mathrm{CO}$ & 27.787 \\
$\mathrm{CO}_{2}$ & 21.223 \\
\hline
\end{tabular}

These gases collide and react in the homogeneous phase inside the cavity. Each type of gas is constantly being produced and consumed. Therefore, the value of each gas cannot be expressed at a particular moment theoretically, and thus the simulation software should be used. The heterogeneous reactions considered in the model are following: (Perkins and Sahajwalla 2008)

$\mathrm{C}+\mathrm{O}_{2} \rightarrow \mathrm{CO}_{2}$

$\mathrm{C}+\mathrm{H}_{2} \mathrm{O} \rightarrow \mathrm{CO}+\mathrm{H}_{2}$

$\mathrm{C}+\mathrm{CO}_{2} \rightarrow 2 \mathrm{CO}$

$\mathrm{C}+2 \mathrm{H}_{2} \rightarrow \mathrm{CH}_{4}$

In the UCG process, the operational parameters are designed according to the object. As mentioned earlier, the target could be the production of syngas, hydrogen, methane or other gases in coal, which this paper aimed to

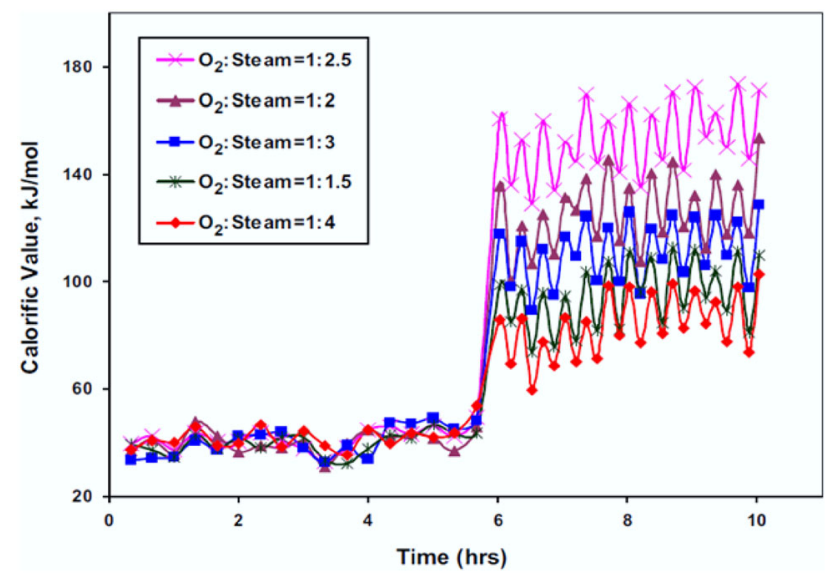

Fig. 2 Effect of steam to oxygen ratio on calorific value of the produced gas (Perkins and Sahajwalla 2008) increase the calorific value of syngas. According to Fig. 2, for having syngas with the highest calorific value, the ratio of steam $\left(\mathrm{H}_{2} \mathrm{O}\right)$ to oxygen $\left(\mathrm{O}_{2}\right)$ should be 2.5 to 1 (Daggupati et al. 2011).

Therefore, Eq. (7) must be multiplied by 2.5 for this ratio to be established. Given the above ratio, rewritten form of the reactions for the cavity growth is given in Table 4. Then, using the Hess's law (Ball 2011), the four reactions in Table 4 have been added together and finally the corresponding formula and enthalpy are obtained as below

$$
\begin{gathered}
5.5 \mathrm{C}+\mathrm{O}_{2}+2.5 \mathrm{H}_{2} \mathrm{O} \rightarrow 4.5 \mathrm{CO}+0.5 \mathrm{H}_{2}+\mathrm{CH}_{4} \\
\Delta \mathrm{H}=+31.5 \mathrm{~kJ} / \mathrm{mol}
\end{gathered}
$$

\subsection{Operational parameters}

In the third step, the total amount of Carbon (C) in the cavity was calculated (Table 3). Also Eq. (10) and stoichiometric coefficients were used to achieve the amount of consumed oxygen molecule and steam for gasifying the intended coal (heterogeneous phase). At this point, the other information required is calculated according to Eqs. (11)-(15). The values of the $\mathrm{H}_{2} \mathrm{O}$ and $\mathrm{O}_{2}$ molecules that react in the heterogeneous phase are listed in Table 5. It should be noted that since there is some amount of $\mathrm{H}_{2} \mathrm{O}$ injection required as the amount of moisture in the coal, this value is extracted from the required one.

The total operation time and injection flow are controllable parameters. The injection flow can be calculated according to Eq. (11), considering the tube diameter and the speed of fluid motion in it. The total operation time can be calculated as (Ball 2011).

$\mathrm{Q}=\mathrm{V} \cdot \mathrm{A}$

where $\mathrm{Q}, \mathrm{V}$, and $\mathrm{A}$ are the injection rate $\left(\mathrm{m}^{3} / \mathrm{s}\right)$, the fluid velocity $(\mathrm{m} / \mathrm{s})$, and the area of injection tube $\left(\mathrm{m}^{2}\right)$, respectively. The gas density can be calculated using Eq. (12).

$\rho_{\text {in }}=\frac{N \times P}{R \times T}$

In this equation, $\rho_{i n}$ is the gas density $\left(\mathrm{mol} / \mathrm{m}^{3}\right)$, and $\mathrm{N}$, $\mathrm{P}, \mathrm{T}$ and $\mathrm{R}$ are the number of gas moles, the pressure $(\mathrm{Pa})$,

Table 4 Changing the coefficients of heterogeneous reactions

\begin{tabular}{lll}
\hline Number & Reactions & Enthalpy $(\mathrm{kJ} / \mathrm{mol})$ \\
\hline 1 & $\mathrm{C}+\mathrm{O}_{2} \rightarrow \mathrm{CO}_{2}$ & $\mathrm{H}=-393 \Delta$ \\
2 & $\mathrm{C}+\mathrm{CO}_{2} \rightarrow 2 \mathrm{CO}$ & $\Delta \mathrm{H}=+172$ \\
3 & $2.5 \mathrm{C}+2.5 \mathrm{H}_{2} \mathrm{O} \rightarrow 2.5 \mathrm{CO}+2.5 \mathrm{H}_{2}$ & $\mathrm{H}=+1312.5 \Delta$ \\
4 & $\mathrm{C}+2 \mathrm{H}_{2} \rightarrow \mathrm{CH}_{4}$ & $\mathrm{H}=-75 \Delta$ \\
\hline
\end{tabular}


Table 5 Values of $\mathrm{H}_{2} \mathrm{O}$ and $\mathrm{O}_{2}$ (in the heterogeneous phase)

\begin{tabular}{lc}
\hline Oxidant & Value $(\mathrm{Mmol})$ \\
\hline Oxygen $\left(\mathrm{O}_{2}\right)$ & 64.465 \\
Steam $\left(\mathrm{H}_{2} \mathrm{O}\right)$ & 117.958 \\
\hline
\end{tabular}

the temperature $(\mathrm{K})$, and the gases constant $(8.31 \mathrm{~J} / \mathrm{mol} \mathrm{K})$, respectively.

Inlet flow can be calculated using the injection well diameter and the fluid flow rate in the well. In this study, numerical models are used. The diameter of the injection well and the velocity of fluid movement in the tube are considered hypothetically. Given the conditions of the UCG project, these values can be altered. In this example, it was assumed that the diameter of the injection well was $0.2 \mathrm{~m}$ and the velocity of the fluid motion in the tube was $1.35 \mathrm{~m} / \mathrm{s}$. In this case, the oxygen injection rate was calculated as $4.23 \times 10^{-2} \mathrm{~m}^{3} / \mathrm{s}$ based on Eq. (11). It was also assumed that the temperature and pressure of the inlet gas tank were $500 \mathrm{~K}$ and $1 \mathrm{MPa}$, respectively. Therefore, the inlet gas density was calculated as $240.56 \mathrm{~mol} / \mathrm{m}^{3}$ based on Eq. (12).

The molar ratio of oxygen injection, according to Eq. 13, was calculated as $10.17 \mathrm{~mol} / \mathrm{s}$, and the total operation time, according to Eq. (14), was obtained as $6.34 \times$ $10^{6} \mathrm{~s}$

$Q_{\mathrm{O}_{2}}^{\prime}=Q_{\mathrm{O}_{2}} \times \rho$

where $\mathrm{Q}_{\mathrm{O}_{2}}^{\prime}$ is the molar ratio of the injected oxygen (mol/s).

$T_{t}=\frac{m o l_{\mathrm{O}_{2}}}{Q_{\mathrm{O}_{2}}^{\prime}}$

where mol $_{\mathrm{O}_{2}}$ is the value of oxygen mole (Table 5) and $\mathrm{T}_{\mathrm{t}}$ is the total operation time $(s)$.

To calculate the steam injection rate, the value of $\mathrm{mol}_{\mathrm{H}_{2} \mathrm{O}}$ (Table 5) and the total operation time $\mathrm{T}_{\mathrm{t}}$ (s) (Eq. (14)) should be used. Therefore, according to Eq. (15), the molar rate of steam injection was calculated as $18.6 \mathrm{~mol} / \mathrm{s}$.

$Q_{\mathrm{H}_{2} \mathrm{O}}^{\prime}=\frac{m o l_{\mathrm{H}_{2} \mathrm{O}}}{T_{t}}$

where, $\mathrm{mol}_{\mathrm{H}_{2} \mathrm{O}}$ is the molar value of steam and $\mathrm{Q}_{\mathrm{H}_{2} \mathrm{O}}^{\prime}$ is the ratio of steam injection $(\mathrm{mol} / \mathrm{s})$.

\section{Numerical solution}

In order to achieve the purpose of the study, a numerical solution with the help of Computational Fluid Dynamics (CFD) using COMSOL software was used. COMSOL
Multiphysics is a simulation software with finite element analysis to solve various problems in engineering, physics and chemistry. This software is used to model the combined effects of fluid flow in porous media as well as mass species transfer, heat transfer and reaction kinetics (COMSOL 2008). The CFD simulation requires specification of boundary conditions including constant flow of gases coming from inlet, constant temperature inlet, constant pressure inlet, constant cavity pressure and temperature, constant volumetric production rate with operation time, the volume of the reactor and the output reservoir are considered continuously. The input parameters of the COMSOL software are presented in Table 6 with respect to the previous steps and other assumptions for simplification. The burning occurred at the temperature from 700 to $900{ }^{\circ} \mathrm{C}$, but it could reach over $1500{ }^{\circ} \mathrm{C}$. The temperature in this study was assumed to be constant as $1000{ }^{\circ} \mathrm{C}$ $(1273 \mathrm{~K})$ and the pressure was set as $1 \mathrm{MPa}$.

Given the constant value of temperature and pressure inside the cavity and in accordance with the ideal gas law (at constant temperature and pressure, each mole of different gases has the same volume), the density of the gas inside the cavity obtained by Eq. (12) was calculated as $94.48 \mathrm{~mol} / \mathrm{m}^{3}$.

In the fourth step, the input parameters and nine main reactions were fed into the COMSOL software chemistry module. Additionally, the reaction kinetics was considered as presented in Tables 7 and 8 .

Nine chemical reactions (both homogeneous and heterogeneous chemical reactions) were considered in this model simultaneously. First the total volume of the reactor was taken into account and then the amount of coal in it was imported. This amount of coal is gradually converted to syngas by the injection of oxygen, until the entire coal is gasified. During this time, five reactions occurred in the homogeneous phase and four reactions occurred in the heterogeneous phase, simultaneously. It should be noted

Table 6 Input parameters (COMSOL software)

\begin{tabular}{ll}
\hline Parameters & Value \\
\hline $\begin{array}{l}\text { Temperature } \\
(\mathrm{K})\end{array}$ & 1273 \\
Pressure & 1 \\
$(\mathrm{MPa})$ & \\
Gas constant $(\mathrm{J} / \mathrm{mol} \mathrm{k})$ & 8.314 \\
Oxygen injection rate $(\mathrm{mol} / \mathrm{s})$ & 10.175 \\
Steam injection rate $(\mathrm{mol} / \mathrm{s})$ & 18.617 \\
Operation time & $6.336 \times 10^{6}$ \\
$(\mathrm{~s})$ & \\
\hline
\end{tabular}


Table 7 Kinetics parameters of homogeneous chemical reactions (Daggupati et al. 2010)

\begin{tabular}{lllrl}
\hline $\begin{array}{l}\text { Reaction } \\
\text { number }\end{array}$ & Rate expression & $\mathrm{A}_{\mathrm{k}}$ & $\mathrm{k} \alpha$ & $\mathrm{E}_{\mathrm{k}}$ \\
\hline 1 & $\mathrm{~K}_{\mathrm{f}, 1}\left[\mathrm{H}_{2}\right]^{1 / 4}\left[\mathrm{O}_{2}\right]^{2 / 3}$ & $2.50 \times 10^{+18}$ & -1.0 & 167.4 \\
2 & $\mathrm{~K}_{\mathrm{f}, 2}[\mathrm{CO}]\left[\mathrm{O}_{2}\right]^{1 / 4}$ & $3.98 \times 10^{+19}$ & 0.0 & 167.4 \\
3 & $\mathrm{~K}_{\mathrm{f}, 3}\left[\mathrm{CH}_{4}\right]^{1 / 2}\left[\mathrm{O}_{2}\right]^{5 /}$ & $4.40 \times 10^{+15}$ & 0.0 & 125.5 \\
& & & & \\
4 & $\mathrm{~K}_{\mathrm{f}, 4}[\mathrm{CO}]\left[\mathrm{H}_{2} \mathrm{O}\right]$ & $2.78 \times 10^{+1}$ & 0.0 & 12.6 \\
5 & $\mathrm{~K}_{\mathrm{f}, 5}\left[\mathrm{CH}_{4}\right]\left[\mathrm{H}_{2} \mathrm{O}\right]$ & $3.12 \times 10^{+1}$ & 0.0 & 30.0 \\
\hline
\end{tabular}

Table 8 Kinetics parameters of heterogeneous chemical reactions (Daggupati et al. 2010)

\begin{tabular}{lllll}
\hline Reaction number & $\mathrm{n}$ & $\mathrm{A}_{\mathrm{k}}$ & $\mathrm{K}^{\alpha}$ & $\mathrm{E}_{\mathrm{k}}$ \\
\hline 6 & 1.0 & $2.503 \times 10^{+17}$ & 1.0 & 179.4 \\
7 & 0.5 & $8.593 \times 10^{+0}$ & 0.5 & 231.0 \\
8 & 0.5 & $8.593 \times 10^{-1}$ & 0.5 & 211.0 \\
9 & 1.0 & $2.337 \times 10^{-6}$ & 1.0 & 150.0 \\
\hline
\end{tabular}

that the reactor type is semi-batch and the initial volume of the linked channel is assumed to be $14 \mathrm{~m}^{3}$.

\subsection{Model results}

There were some interesting results from the compounds of gas produced and the calorific value. The model results are presented in Fig. 3. The quantities and components of gas produced are presented in Table 9. Further, the volume of the produced gas at the pressure and temperature of $1273 \mathrm{~K}$

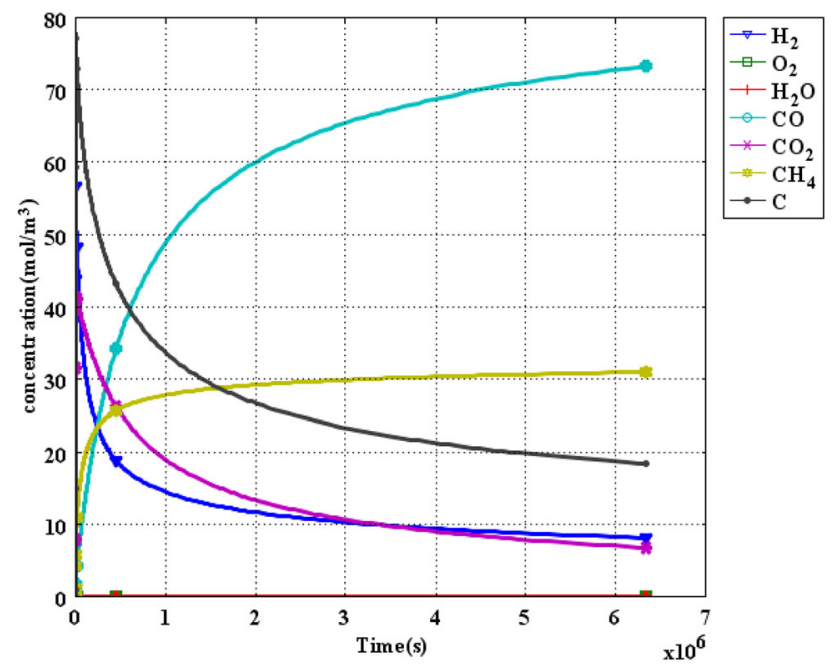

Fig. 3 Concentration and components of produced gas after initial run of the model
Table 9 Values and components of the produced gas after the initial run of the model

\begin{tabular}{ll}
\hline Components of syngas & Value $\left(\mathrm{Mm}^{3}\right)$ \\
\hline $\mathrm{CO}_{2}$ & 0.2629 \\
$\mathrm{H}_{2}$ & 0.3152 \\
$\mathrm{CH}_{4}$ & 1.2002 \\
$\mathrm{CO}$ & 2.8304 \\
Total & 4.6087 \\
\hline
\end{tabular}

and $1 \mathrm{MPa}$ (cavity pressure and temperature) respectively are presented in Table 9.

As shown in Fig. 3, not all the carbon in the cavity is still converted (black curve in the figure) and $1503 \mathrm{~m}^{3}$ of coal remain in the panel. The reason for this phenomenon is that not all inlet oxygen are involved in the heterogeneous phase and part of it is consumed in the homogeneous phase. To gasify the remaining coal, the oxygen injection rate can be considered higher (i.e., to increase the rate of injecting oxygen or steam, or both of them), the operation time could be prolonged and the pressure could be larger, or a combination of these conditions can be used. Next, four scenarios have been designed and investigated to gasify all the coal within the cavity. Thereafter, several other scenarios have been investigated by changing the operating parameters simultaneously. It should be noted that across all scenarios, the distance between the injection and production wells was assumed to be constant (constant volume).

\subsubsection{Scenario 1 (increasing the oxygen injection rate)}

To gasify the remaining coal within the cavity, it was assumed that all operating parameters were constant at the initial modeling stage and only the oxygen injection rate increased. With trial and error, this value increased until all the remaining coal was gasified. Finally, the oxygen injection rate reached $57.6 \mathrm{~mol} / \mathrm{s}$. In this case, the ratio of steam to oxygen injection was 0.44. After running the model, the results were presented in Fig. 4 and Table 10 at the temperature of $1273 \mathrm{~K}$ and the pressure of $1 \mathrm{MPa}$.

As revealed in Fig. 4, by increasing the oxygen injection rate, the value of $\mathrm{CH}_{4}$ and $\mathrm{CO}$ decreased while that of $\mathrm{H}_{2}$ increased. Further, the calorific value of the produced gas diminished. This is due to the excessive burning of carbon monoxide and methane, despite the high level of oxidant within the cavity. In this scenario, a lot of water $\left(\mathrm{H}_{2} \mathrm{O}\right)$ was produced, but according to reactions 4 and 5, when $\mathrm{CO}$ and $\mathrm{CH}_{4}$ were consumed, hydrogen was produced. So hydrogen is also relatively high compared to other components. 


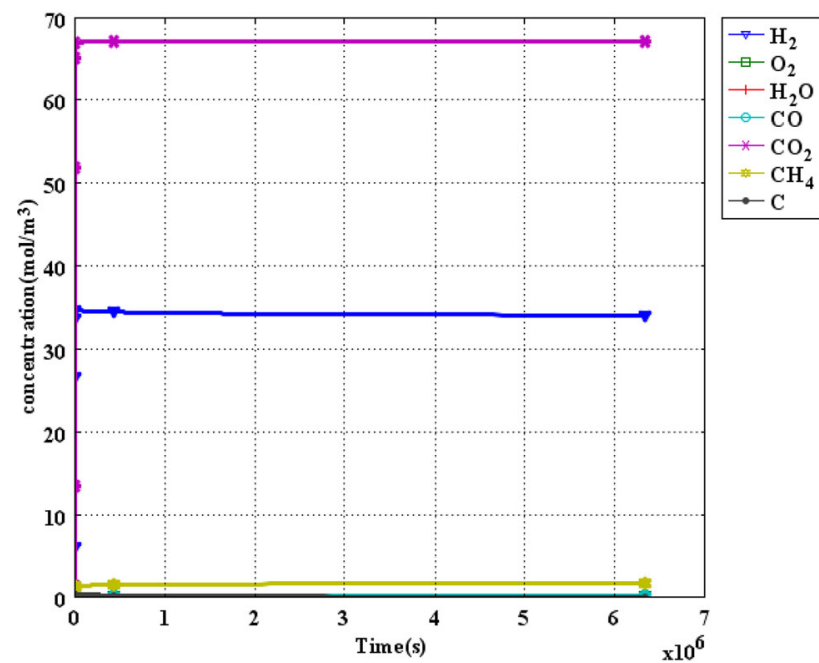

Fig. 4 Concentration and components of produced gas in scenario 1

Table 10 Values and components of the produced gas in scenario 1, 2,3 and 4

\begin{tabular}{lllllr}
\hline \multirow{2}{*}{ Scenario number } & \multicolumn{4}{l}{$\begin{array}{l}\text { Values and components of the produced gas } \\
\text { (Mmol) }\end{array}$} \\
\cline { 2 - 6 } & $\mathrm{CO}_{2}$ & $\mathrm{CO}$ & $\mathrm{CH}_{4}$ & $\mathrm{H}_{2}$ & \multicolumn{1}{c}{ Total } \\
\hline 1 & 4.8507 & 0.0202 & 0.1261 & 2.4633 & 7.4603 \\
2 & 4.9470 & 0.0072 & 0.0238 & 9.2128 & 14.1908 \\
3 & 2.2928 & 1.3829 & 1.2645 & 1.4353 & 6.3755 \\
4 & 1.4124 & 0.0358 & 0.2175 & 1.3024 & 2.9681 \\
\hline
\end{tabular}

\subsubsection{Scenario 2 (increasing the steam injection rate)}

In this case, it was assumed that all of the operating parameters of the initial modeling stage were constant and only the steam injection rate was elevated, until all the coal available was gasified in the cavity. Finally, the steam injection rate reached $123.04 \mathrm{~mol} / \mathrm{s}$. In this case, the ratio of steam to oxygen injection is 12 . Then, after running the model, the results were obtained as shown in Fig. 5 and Table 10 at the temperature of $1273 \mathrm{~K}$ and the pressure of $1 \mathrm{MPa}$.

In this case, the values of methane and carbon monoxide decreased, while the value of hydrogen grew dramatically. As in scenario 1, this could be due to excessive burning of carbon monoxide and methane, despite high levels of oxidant (steam) in the cavity. Also in this case, it seems that in the UCG process for hydrogen production, if the steam injection rate increases, the result will improve.

One of the benefits of this method is that all chemical reactions are carried out, which results in oxygen and steam entering the required amount of cavities, with no output. Because if oxygen and steam leave the other side, there is almost nothing to do. After all the coal in the cavity

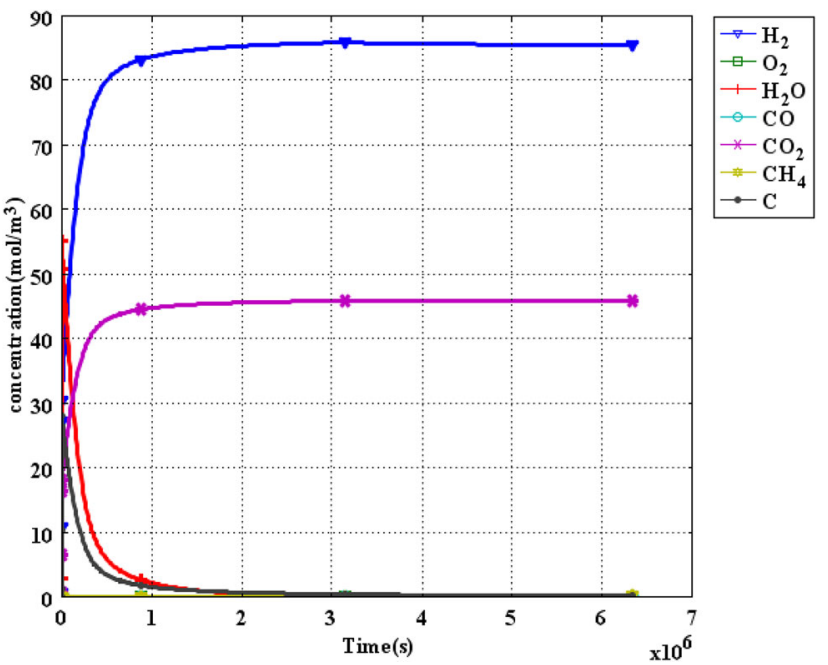

Fig. 5 Concentration and components of produced gas in scenario 2

has been gasified, the oxygen injection process stops. Therefore, excess oxygen is not injected. Also, since the cavity temperature is assumed to be in excess of $1273 \mathrm{~K}$, it is assumed that the steam will remain as vapor and will not become liquid (water), as this will probably cause the reaction to quench.

\subsubsection{Scenario 3 (increasing the operation time)}

In this case, it was assumed that all the operating parameters in the initial modeling stage were constant and only the operation time was increased. Prolonging operation time continued until gasifying all the coal available within the cavity. Finally, the operation time reached 147 days. The results are illustrated in Fig. 6 and Table 10 at the temperature of $1273 \mathrm{~K}$ and the pressure of $1 \mathrm{MPa}$.

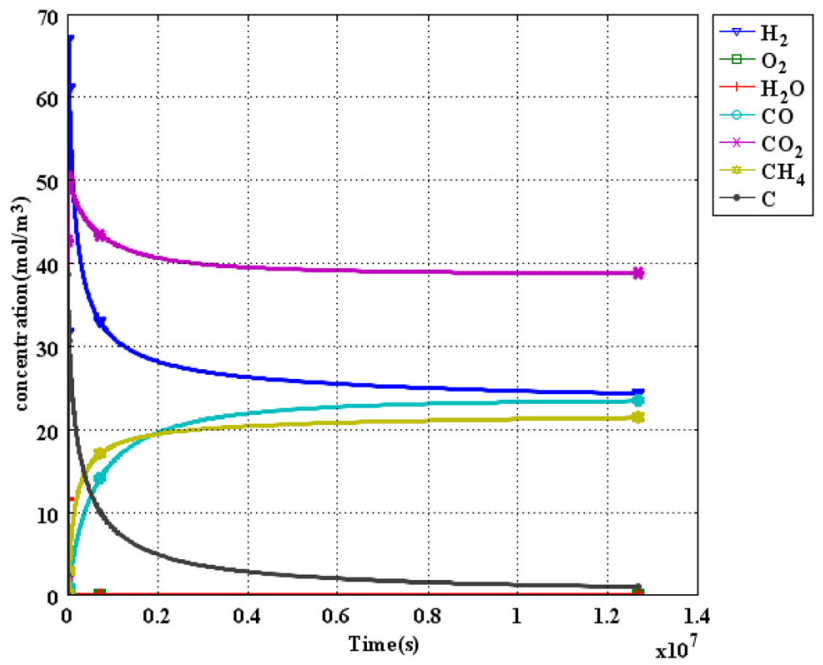

Fig. 6 Concentration and components of produced gas in scenario 3 
In this case, the values of methane and hydrogen in the syngas increased and the value of carbon monoxide was kept high. The calorific value of the produced gas rose in this case.

\subsubsection{Scenario 4 (increasing the pressure)}

In general, the increase in pressure leads to a further increase in the dimensions of the cavity (Sarraf Shirazi 2012). Therefore, if all the parameters in the initial design were constant and only the pressure increased, at a constant time, the rate of coal gasification would increase, meaning that the reaction intensity would be higher in the heterogeneous phase.

In this case, it was assumed that all of the operating parameters in the initial modeling stage were constant and only the operating pressure increased until gasifying the total coal available within the cavity. Finally, the pressure was increased to $3 \mathrm{MPa}$. The results at the temperature of $1273 \mathrm{~K}$ and the pressure of $3 \mathrm{MPa}$ are shown in Fig. 7 and Table 10.

In this case, the costs (except the cost of increasing injection pressure) will not increase and it seems to be cost effective economically.

\subsection{Comparison of four scenarios}

To compare each of the four developed scenarios, the volume and content of the produced gas should be expressed at the same pressure and temperature. In this section, in order to compare the value of the produced gas in each scenario, the temperature and pressure of the produced gas in each case were calculated at $1273 \mathrm{~K}$ and $1 \mathrm{MPa}$, respectively. In scenario 4 (increasing the pressure), the volume of the produced gas declined from 3 to

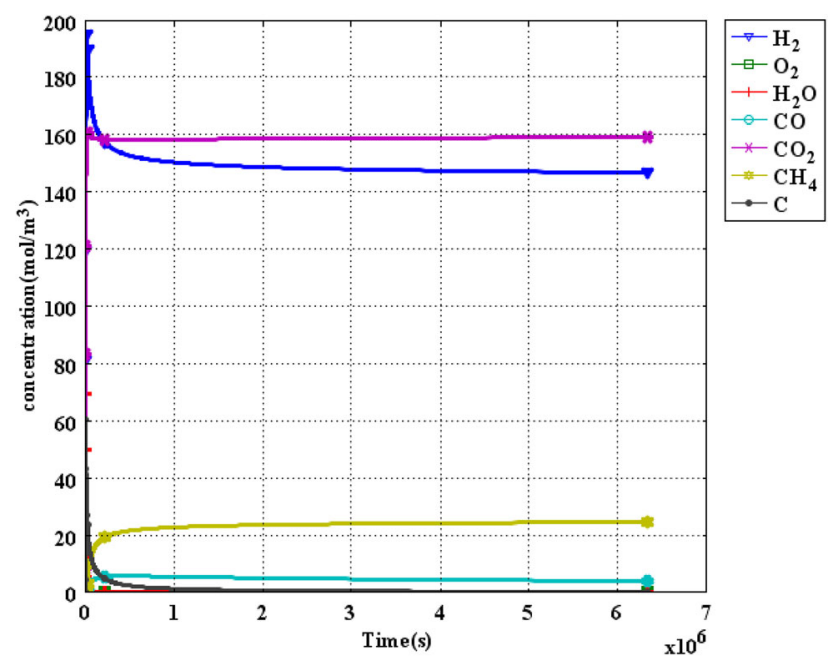

Fig. 7 Concentration and components of produced gas in scenario 4
$1 \mathrm{MPa}$ using Eq. (12). The results are shown in Table 11 and Fig. 8.

In Fig. 8, the volumes of the produced gas in each scenario are compared. As can be seen, the highest amount of $\mathrm{CH}_{4}$ and $\mathrm{CO}$ was obtained in scenario 3, while the highest amount of $\mathrm{H}_{2}$ and $\mathrm{CO}_{2}$ was obtained in scenario 2 . In Fig. 9, the value of the produced gas in each scenario is compared. As shown in this figure, the highest amount of gas was produced in scenarios 2, 4, 1 and 3, respectively.

In order to achieve the main goal of this study, the calorific values of the produced gas in each scenario were compared to each other. At the temperature of $25^{\circ} \mathrm{C}$ and the pressure of $1 \mathrm{~atm}$, the calorific value of hydrogen was $285.8 \mathrm{~kJ} / \mathrm{mol}$, the calorific value of carbon monoxide was $283.0 \mathrm{~kJ} / \mathrm{mol}$, and the calorific value of methane was $890.8 \mathrm{~kJ} / \mathrm{mol}$, while carbon dioxide had no calorific value (Haynes 2014). Accordingly, the value of molar components of the produced gas was calculated for each scenario, then these values were multiplied by the ratios mentioned for every type of gas. For this purpose, Eq. (12) was used. The results are reported in Table 12 for each scenario.

According to Fig. 10, the highest calorific value of the produced gas was observed in scenarios 3, 4, 2, and 1 with values of $302.41 \mathrm{~kJ} / \mathrm{mol}, 194.33 \mathrm{~kJ} / \mathrm{mol}, 187.18 \mathrm{~kJ} / \mathrm{mol}$, and $110.19 \mathrm{~kJ} / \mathrm{mol}$, respectively.

In scenario 3 , the amount of gasoline produced was at the highest level as the operating time was prolonged. In scenario 4 , the probability of $\mathrm{H}_{2} \mathrm{O}, \mathrm{O}_{2}, \mathrm{H}_{2}$ and $\mathrm{CO}_{2}$ colliding in the cavity walls is increased, so the reaction is increased in a heterogeneous phase and $\mathrm{CO}$ and $\mathrm{CH}_{4}$ are produced at higher values compared with scenario 1 and 2 . In scenarios 1 and 2 , the lowest calorific value was observed for the produced gas. As mentioned earlier, despite high oxygen in scenarios 1 and 2 , most of the existing $\mathrm{CH}_{4}$ and $\mathrm{CO}$ content is burned and thus the calorific value of syngas has decreased. Given the validity of the proposed model, the results obtained from this model are fully consistent with the findings of other studies regarding the influence of operational parameters on the UCG process (Kasani and Chalaturnyk 2017; Perkins 2005; Sarraf Shirazi 2012; Daggupati et al. 2010; Perkins and

Table 11 Comparing the composition and volume of the produced gas in each scenario

\begin{tabular}{llrll}
\hline Components of syngas & \multicolumn{5}{l}{ Number of scenarios } \\
\cline { 2 - 5 } & 1 & \multicolumn{1}{l}{2} & \multicolumn{1}{l}{3} & \multicolumn{1}{l}{4} \\
\hline $\mathrm{CO}_{2}\left(\mathrm{Mm}^{3}\right)$ & 4.8507 & 4.9470 & 2.2928 & 4.2371 \\
$\mathrm{H}_{2}\left(\mathrm{Mm}^{3}\right)$ & 2.4633 & 9.2128 & 1.4353 & 3.9071 \\
$\mathrm{CH}_{4}\left(\mathrm{Mm}^{3}\right)$ & 0.1261 & 0.0238 & 1.2645 & 0.6525 \\
$\mathrm{CO}\left(\mathrm{Mm}^{3}\right)$ & 0.0202 & 0.0072 & 1.3829 & 0.1074 \\
Total $\left(\mathrm{Mm}^{3}\right)$ & 7.4603 & 14.1908 & 6.3755 & 8.9041 \\
\hline
\end{tabular}




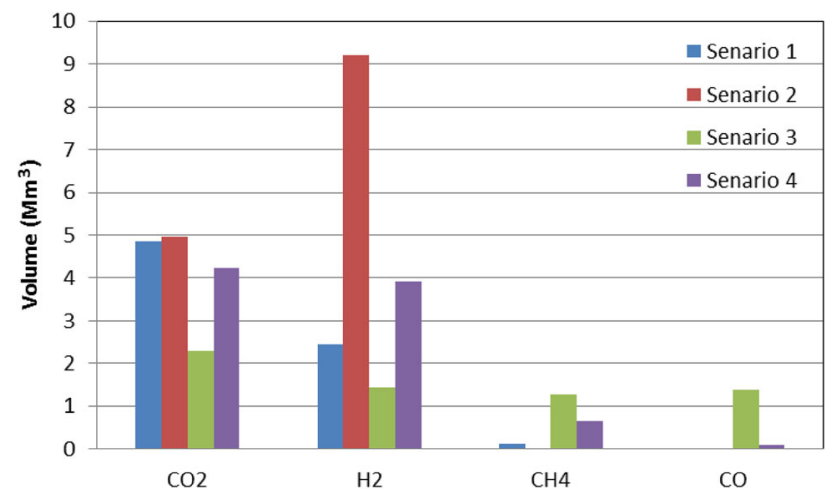

Fig. 8 Comparing the volume of the produced gas in each scenario

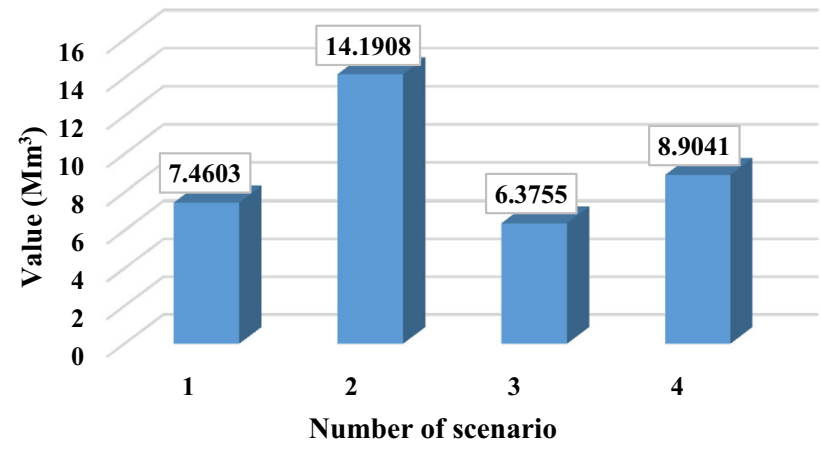

Fig. 9 Comparing the total produced gas in each scenario

Sahajwalla 2008; Daggupati et al. 2011; Zogala and Janoszek 2015; Wiatowski et al. 2016; Prabu and Jayanti 2011).

\section{Discussion}

In each scenario in the previous steps, all of the parameters were considered as constant and only one parameter was altered. Scenarios 1-4 indicated the sensitivity analysis for each operating parameters. Considering the possibility of simultaneously changing these parameters, many combined scenarios can be considered. For this purpose, several more

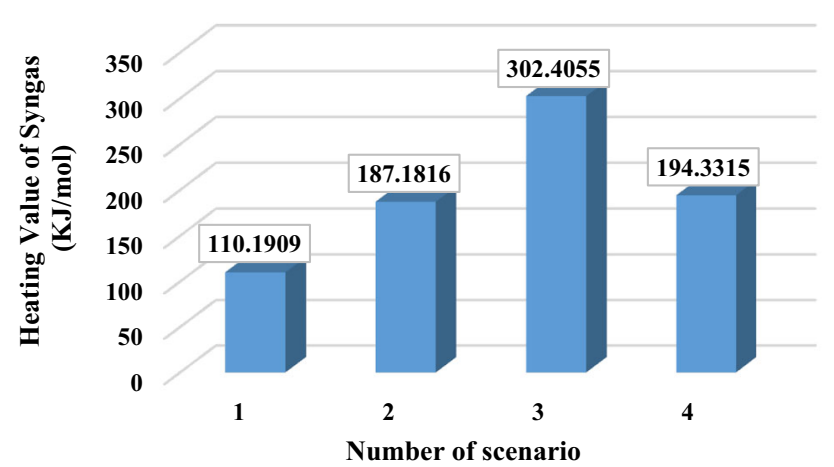

Fig. 10 Comparing the calorific value of the produced gas in each scenario

scenarios have been investigated by simultaneous changing in these parameters. In scenario 5, the cavity pressure and the operation time have been increased simultaneously. In scenario 6 , the oxygen and steam injection rates have been increased in such a way that the ratio of 2.5 to 1 is preserved. In scenario 7, all of the four parameters were enhanced simultaneously. In scenario 8 , the time and the rate of steam injection is increased. The calorific value and the amount of the produced gas for each scenario are listed in Table 13.

As shown in Table 13, the highest calorific value of the produced gas among the eight available scenarios is in scenario 5 with $346.94 \mathrm{~kJ} / \mathrm{mol}$. Among the four combined scenarios, the highest value of the produced gas is in scenarios 8, 6, 7, and 5, respectively. However, the highest value of the produced gas among the eight scenarios is in scenario 2 with $1340 \mathrm{Mmol}(22380.64 \mathrm{Mg}$ ).

It is necessary to mention that after the initial implementation of the model the calorific value of syngas has been obtained $425.331 \mathrm{~kJ} / \mathrm{mol}$. The reason for re-running the model and continuing the process in eight different scenarios was that the total coal in the panel was not gasified (in this research the dimensions of the panels were considered constant). Therefore, in each different scenarios the ratio and value of one or more parameters have been changed simultaneously in order to gasification all the coal in the panel. This subject has reduced the calorific value of the produced gas compared

Table 12 The calorific value of the produced gas in scenario 1, 2, 3 and 4

\begin{tabular}{|c|c|c|c|c|c|c|}
\hline \multirow[t]{2}{*}{ Scenario number } & \multicolumn{5}{|c|}{ Values and components of the produced gas (Mmol) } & \multirow{2}{*}{$\begin{array}{l}\text { Calorific value of syngas } \\
(\mathrm{kJ} / \mathrm{mol})\end{array}$} \\
\hline & $\mathrm{CO}_{2}$ & $\mathrm{CO}$ & $\mathrm{CH}_{4}$ & $\mathrm{H}_{2}$ & Total & \\
\hline 1 & 458.3169 & 1.9086 & 11.9145 & 232.7442 & 704.8842 & 110.1909 \\
\hline 2 & 467.4158 & 0.6803 & 2.2487 & 870.4686 & 1340.8134 & 187.1816 \\
\hline 3 & 216.6345 & 130.6629 & 119.4759 & 135.6139 & 602.3872 & 302.4055 \\
\hline 4 & 400.3411 & 10.1476 & 61.6513 & 369.1612 & 840.3012 & 194.3315 \\
\hline
\end{tabular}


Table 13 The calorific value of the produced gas with simultaneous change in operating parameters

\begin{tabular}{|c|c|c|c|c|c|c|c|}
\hline \multirow[t]{2}{*}{ Scenario number } & \multirow[t]{2}{*}{ Considerations } & \multicolumn{5}{|c|}{ Values and components of the produced gas ( $\mathrm{Mmol})$} & \multirow{2}{*}{$\begin{array}{l}\text { Calorific value } \\
\text { of syngas }(\mathrm{kJ} / \mathrm{mol})\end{array}$} \\
\hline & & $\mathrm{CO}_{2}$ & $\mathrm{CO}$ & $\mathrm{CH}_{4}$ & $\mathrm{H}_{2}$ & Total & \\
\hline 5 & $\begin{array}{l}\text { Increasing the operation time to } 127 \text { day } \\
\text { Increasing the cavity pressure to } 2 \mathrm{MPa}\end{array}$ & 163.82 & 171.19 & 133.27 & 76.86 & 545.14 & 346.94 \\
\hline 6 & $\begin{array}{l}\text { Increasing the steam injection rate to } 50 \mathrm{~mol} / \mathrm{s} \\
\text { Increasing the oxygen injection rate to } 20 \mathrm{~mol} / \mathrm{s}\end{array}$ & 285.47 & 69.52 & 110.57 & 234.28 & 699.84 & 264.53 \\
\hline 7 & $\begin{array}{l}\text { Increasing the cavity pressure to } 1.8 \mathrm{MPa} \\
\text { Increasing the operation time to } 116 \mathrm{day} \\
\text { Increasing the steam injection rate to } 30 \mathrm{~mol} / \mathrm{s} \\
\text { Increasing the oxygen injection rate to } 12 \mathrm{~mol} / \mathrm{s}\end{array}$ & 270.87 & 68.49 & 130.74 & 177.13 & 647.23 & 288.11 \\
\hline 8 & $\begin{array}{l}\text { Increasing the operation time to } 122 \text { day } \\
\text { Increasing the steam injection rate to } 33 \mathrm{~mol} / \mathrm{s}\end{array}$ & 281.41 & 68.30 & 118.48 & 248.88 & 717.07 & 273.34 \\
\hline
\end{tabular}

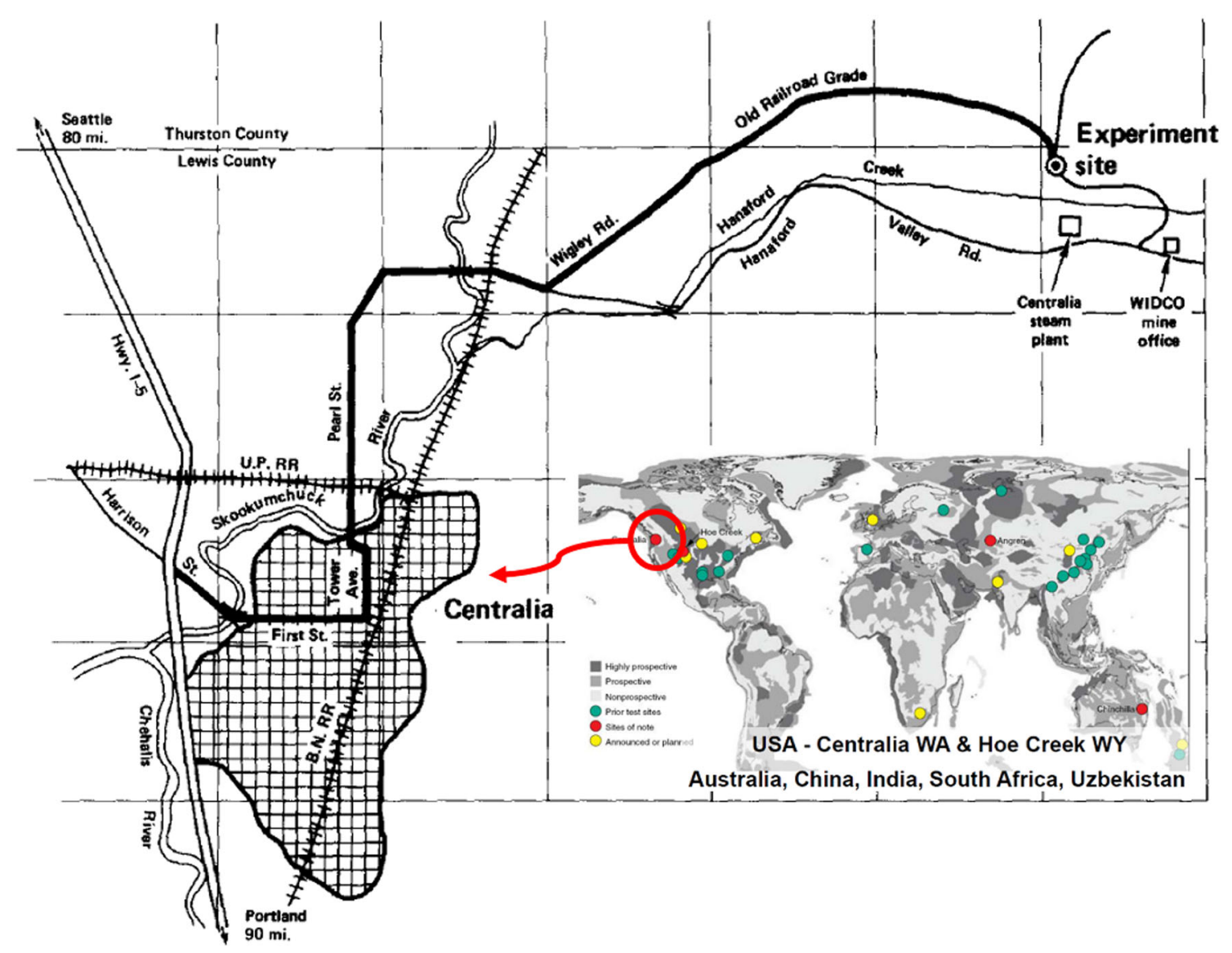

Fig. 11 Geological location of Centralia UCG pilot (Hill 1982; Lawrence Livermore National Laboratory 2007)

to the initial run of the model. This matter indicates that the design and determination of operational parameters has been very advantageous at initial section. Therefore, by reducing dimensions of the panel, the ratio between the operating parameters can be maintained constant until the end of operation and produce syngas with higher calorific value.

\section{Model validation}

The model which is presented in this study has a huge potential for evaluation of operational parameters before implementing UCG process. Therefore, model validation was done by comparing to the real field data of Centralia LBK-1 UCG pilot. 
Table 14 Input parameters for simulation LBK-1 UCG pilot (Hill 1982)

\begin{tabular}{|c|c|c|c|c|c|c|c|c|c|c|c|}
\hline Pressure & $\begin{array}{l}\text { Temperature } \\
(\mathrm{K})\end{array}$ & $\begin{array}{l}\text { Parameters } \\
(\mathrm{MPa})\end{array}$ & $\begin{array}{l}\text { Gas } \\
\text { constant } \\
(\mathrm{J} / \mathrm{mol} \mathrm{k})\end{array}$ & $\begin{array}{l}\text { Oxygen } \\
\text { injection } \\
\text { rate }(\mathrm{mol} / \mathrm{s})\end{array}$ & $\begin{array}{l}\text { Steam } \\
\text { injection } \\
\text { rate (mol/ } \\
\mathrm{s})\end{array}$ & $\begin{array}{l}\text { Operation } \\
\text { time (s) }\end{array}$ & $\begin{array}{l}\text { Fixed } \\
\text { carbon } \\
(\% w)\end{array}$ & $\begin{array}{l}\text { Moisture } \\
(\% \mathrm{w})\end{array}$ & $\begin{array}{l}\text { Ash } \\
(\% \mathrm{w})\end{array}$ & $\begin{array}{l}\text { Volatile } \\
\text { matter } \\
(\% \mathrm{w})\end{array}$ & $\begin{array}{l}\text { Density } \\
\left(\text { ton } / \mathrm{m}^{3} \text { ) }\right.\end{array}$ \\
\hline 0.125 & 8.31441 & 2.35 & 7.05 & 95904 & 35.5 & 21.6 & 14.4 & 28.5 & 1.38 & 1273 & Value \\
\hline
\end{tabular}

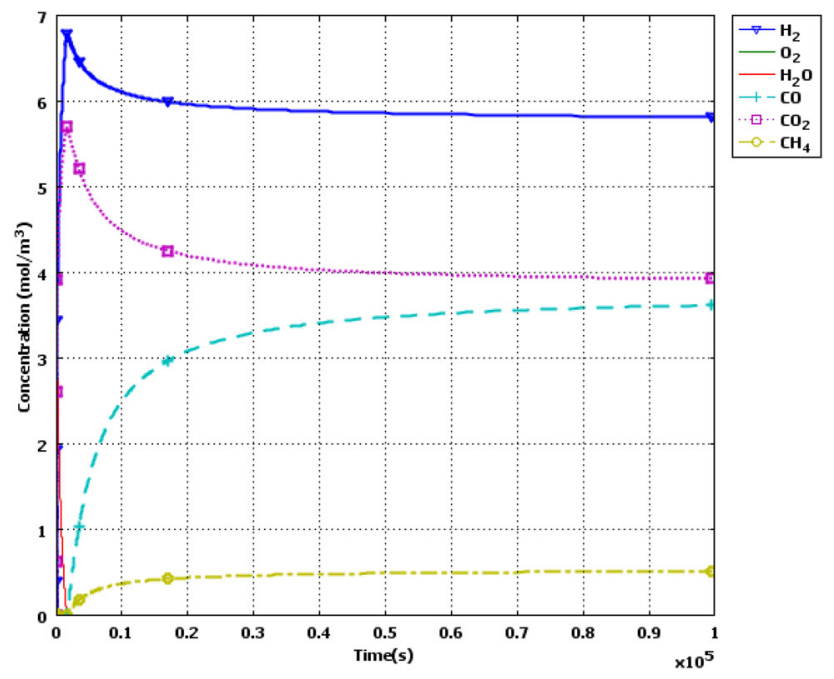

Fig. 12 Concentration and components of produced gas after simulation LBK-1 UCG pilot

\subsection{Simulation for Centralia LBK-1 pilot}

UCG pilot for LBK-1 has been conducted in the USA (Centralia). Geological location of this UCG pilot project is shown in Fig. 11. Technical and geological information for this pilot is shown in Table 14. It is necessary to mention that in this section to construct the model, used data are field data and interpolation data.

According to the presented model, the amount and components of produced gas for LBK-1 UCG pilot is shown in Fig. 12 and Table 15.

The result of this model and field data [Kostúr and Kačúr 2008] of LBK-1 is shown in Table 16. It is clear that the error average percentage between the model prediction and field data is less than $1 \%$. The obtained results are very close to each other, and this confirms the authenticity of the presented model. The differences amounts occurred in this experiment could happen because of gas leakage, temperature variation, moisture and etc.

\section{Conclusion}

One of the important issues in UCG projects is determining the optimal operational parameters to gasify the total coal available between the wells (in panels). In this paper, a
Table 15 Concentration of produced gas after simulation LBK-1 UCG pilot

\begin{tabular}{lllll}
\hline Produced gas & $\mathrm{H}_{2}$ & $\mathrm{CO}_{2}$ & $\mathrm{CO}$ & $\mathrm{CH}_{4}$ \\
\hline $\begin{array}{l}\text { Amount } \\
\left(\mathrm{mol} / \mathrm{m}^{3}\right)\end{array}$ & 5.8 & 3.9 & 3.6 & 0.5 \\
\hline
\end{tabular}

Table 16 Concentration of produced gas after simulation LBK-1 UCG pilot

\begin{tabular}{lrrrrl}
\hline & $\mathrm{H}_{2}$ & $\mathrm{CO}_{2}$ & $\mathrm{CO}$ & $\mathrm{CH}_{4}$ & \%Error average \\
\hline Model prediction(\%) & 41.7 & 28.1 & 25.9 & 3.6 & - \\
Field data (\%) & 40.9 & 27.1 & 24.1 & 3.9 & - \\
\% Error (+) & 0.8 & 1 & 1.8 & 0.3 & 0.97 \\
\hline
\end{tabular}

model was developed to increase the calorific value of syngas and to gasify the total coal in cavity simultaneously. The results of the initial run of the model by COMSOL software indicated that some coal in the cavity was not gasified. So initially, four scenarios were developed to gasify the remaining coal in the cavity. These four scenarios were included: increasing oxygen injection rate (scenario 1), increasing steam injection rate (scenario 2), increasing operation time (scenario 3), and increasing cavity pressure (scenario 4). The most important results obtained from these scenarios are as follows:

(1) The highest volume of the produced gas was observed in scenarios 2, 4, 1 and 3, respectively. For producing syngas with a higher calorific value; the operation time, cavity pressure, steam injection rate, and oxygen injection rate showed the most positive effect, respectively.

(2) In scenario 2 (increasing the steam injection rates), the ratio of steam injection to oxygen was about 12 . Although the calorific value of the produced gas was reduced in this case, the amount of hydrogen in the produced gas grew significantly. Thus, from among the four different scenarios, this scenario was the best for hydrogen production from the UCG process.

(3) In the following four other scenarios were also developed by changing the operational parameters 
simultaneously. Finally, out of the eight investigated scenarios, the highest calorific value of the produced gas was obtained in scenario 5 with $346.94 \mathrm{~kJ} / \mathrm{mol}$, while the highest amount of the produced gas was obtained in scenario 2 with $22380.64 \mathrm{Mg}$. In the end a model validation was done by comparing to the real field data of Centralia LBK-1 UCG pilot, the result shown that the error average percentage between the model prediction and field data is less than $1 \%$ and so this model is very close to reality. To develop this research, countless scenarios can be considered. Therefore, it is suggested that through changing them simultaneously and considering other operational parameters (such as cavity temperature), the optimal ratio of all operational parameters be investigated to produce syngas with the highest calorific value.

Open Access This article is licensed under a Creative Commons Attribution 4.0 International License, which permits use, sharing, adaptation, distribution and reproduction in any medium or format, as long as you give appropriate credit to the original author(s) and the source, provide a link to the Creative Commons licence, and indicate if changes were made. The images or other third party material in this article are included in the article's Creative Commons licence, unless indicated otherwise in a credit line to the material. If material is not included in the article's Creative Commons licence and your intended use is not permitted by statutory regulation or exceeds the permitted use, you will need to obtain permission directly from the copyright holder. To view a copy of this licence, visit http://creativecommons. org/licenses/by/4.0/.

\section{REFERENCES}

Andrianopoulos E, Korre A, Durucan S (2015) Chemical process modeling of underground coal gasification and evaluation of produced gas quality for end use. Energy Procedia 76:444-453

Ball DW (2011) Beginning chemistry. pp. 382, 389, 316. Retrieved December 13, 2018 from https://2012books.lardbucket.org/ books/beginning-chemistry

Comsol A (2008) COMSOL Multiphysics version 3.5, User's guide and reference guide. COMSOL AB, Burlington

Couch GR (2009) Underground coal gasification. IEA Clean Coal Centre, International Energy Agency, London, ISBN 978-929029-471-9. http://www.iea-coal.org.uk.

Daggupati S, Mandapati RN, Mahajani SM, Ganesh A, Mathur DK, Sharma RK, Aghalayam P (2010) Laboratory studies on combustion cavity growth in lignite coal blocks in the context of underground coal gasification. Energy 35(6):2374-2386

Daggupati S, Mandapati RN, Mahajani SM, Ganesh A, Sapru RK, Sharma RK, Aghalayam P (2011) Laboratory studies on cavity growth and produced gas composition in the context of underground coal gasification. Energy 36(3):1776-1784

Haynes WM (ed) (2014) CRC handbook of chemistry and physics. CRC Press, Boca Raton
Hill RW (1982) Summary report on large block experiments in underground coal gasification, Tono Basin, Washington: Experimental description and data analysis, vol 1. University of California, Lawrence Livermore Laboratory, California

Iwaszenko S, Howaniec N, Smoliński A (2019) Determination of random pore model parameters for underground coal gasification simulation. Energy 166:972-978

Jiang L, Chen Z, Ali SMF (2018) General hydro-geological impact of cleats on underground coal gasification. Fuel 224:128-137

Jowkar A, Sereshki F, Najafi M (2018) A new model for evaluation of cavity shape and volume during Underground Coal Gasification process. Energy 148:756-765

Kasani HA, Chalaturnyk RJ (2017) Coupled reservoir and geomechanical simulation for a deep underground coal gasification project. J Nat Gas Sci Eng 37:487-501

Kostúr K, Kačúr J (2008) The monitoring and control of underground coal gasification in laboratory conditions. Acta Montan Slovaca 13(1):111-117

Kumari G, Vairakannu P (2018) $\mathrm{CO}_{2}$-air based two stage gasification of low ash and high ash Indian coals in the context of underground coal gasification. Energy 143:822-832

Laciak M, Kostúr K, Durdán M, Kačur J, Flegner P (2016) The analysis of the underground coal gasification in experimental equipment. Energy 114:332-343

Nourozieh H, Kariznovi M, Chen Z, Abedi J (2010) Simulation study of underground coal gasification in Alberta reservoirs: geological structure and process modeling. Energy Fuels 24(6):3540-3550

Perkins GMP (2005) Mathematical modelling of underground coal gasification. University of New South Wales, Kensington, p 257

Perkins G, Sahajwalla V (2008) Steady-state model for estimating gas production from underground coal gasification. Energy Fuels 22(6):3902-3914

Perkins Greg, Vairakannu Prabu (2017) Considerations for oxidant and gasifying medium selection in underground coal gasification. Fuel Process Technol 165:145-154

Prabu V, Jayanti S (2011) Simulation of cavity formation in underground coal gasification using bore hole combustion experiments. Energy 36(10):5854-5864

Robert F, Joseph W (1996) In situ gasification and combustion of coal. In: Hartman H (ed) SME Handbook. Society for Mining, Metallurgy and Exploration, Littleton

Sarraf Shirazi A (2012) CFD simulation of underground coal gasification. In: masters abstracts international, vol. 51, no. 03

Smit H, Werner GJ (1976) Coal conversion technology. Noyes Data Corporation, London

$\mathrm{Su} F$ et al (2018) Monitoring and evaluation of simulated underground coal gasification in an ex situ experimental artificial coal seam system. Appl Energy 223(2018):82-92

Walter K (2007) Fire in the hole-Underground coal gasification may provide a secure energy supply and reduce greenhouse gas emissions. Lawrence Livermore National Laboratory Science \& Technology Review

Wiatowski M, Kapusta K, Ludwik-Pardała M, Stańczyk K (2016) Exsitu experimental simulation of hard coal underground gasification at elevated pressure. Fuel 184:401-408

www.lincenergy.com 2017

Żogała A, Janoszek T (2015) CFD simulations of influence of steam in gasification agent on parameters of UCG process. J Sustain Min 14(1):2-11 